\title{
Unprecedented Diastereoselective Arylogous Michael Addition of Unactivated Phthalides
}

\author{
Marina Sicignano, ${ }^{[a]}$ Rosaria Schettini, ${ }^{[a]}$ Luisa Sica, ${ }^{[a]}$ Giovanni Pierri, ${ }^{[a]}$ Francesco De Riccardis, ${ }^{[a]}$ \\ Irene Izzo, ${ }^{[a]}$ Bholanath Maity, ${ }^{[b]}$ Yury Minenkov, ${ }^{[b]}$ Luigi Cavallo, ${ }^{*[b]}$ and Giorgio Della Sala*[a]
}

\begin{abstract}
Abtract: The first highly enantioselective arylogous Michael reaction (ARM) of 3-unsubstituted phthalides has been described. This phase-transfer methodology, using catalytic amounts of $\mathrm{KOH} / 18$ crown-6 catalyst in mesitylene in the presence of $\mathrm{N}, \mathrm{O}$ bis(trimethylsilyl)acetamide (BSA), gives access to a broad range of 3-monosubstituted phthalides with high syn-diastereoselectivities and good yields, starting from 3-unsubstituted derivatives and
\end{abstract}

diverse $\alpha, \beta$-unsaturated carbonyl compounds. The reaction also applies to unactivated 3-alkyl phthalides, affording 3,3-dialkyl derivatives. A plausible mechanism has been suggested. DFT analysis of possible transition states gives a rationale of the high syn-diastereoselectivity observed and its correlation with solvent's dielectric constant<smiles>CCCCC1OC(=O)c2ccccc21</smiles>

3-Butylphthalide<smiles>CCCCC[C@H]1OC(=O)c2cc(O)c(O)c(O)c21</smiles>

Cytosporone E<smiles>C/C=C/C1CC(=O)C(C2OC(=O)c3cc(OC)cc(OC)c32)=CO1</smiles>

Vermistatin<smiles>O=C1OC(Cc2ccccc2)c2cccc(O)c21</smiles>

Typhaphthalide

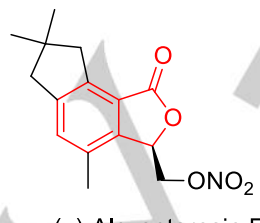

(-)-Alcyopterosin E

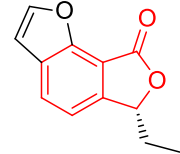

$(R)$-concentricolide

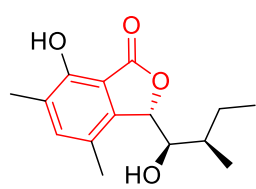

Chrysoarticulin C<smiles>COc1cc(O)cc2c1C(=O)O[C@H]2CCCCCC1CCC[C@@]2(CCCO2)O1</smiles>

Spirolaxine

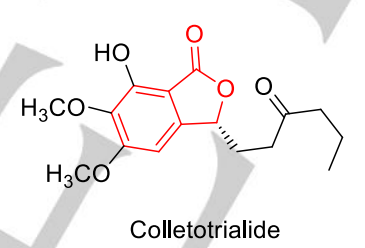

Colletotrialide<smiles>COc1ccc2c(c1OC)C(=O)OC2[C@@H]1c2c(cc3c(c2OC)OCO3)CCN1C</smiles>

$\alpha$-Noscapine<smiles>CC1OC(=O)c2c(O)c(O)c3c(c21)CCC(C)(C)O3</smiles>

Fuscinarin

Figure 1. Selected examples of natural occurring bioactive 3-monosubstituted phthalides.

\section{Introduction}

Phthalides, or isobenzofuranones, are natural occurring aromatic butyrolactones isolated in large number from plants and fungi and exhibiting an impressive range of interesting

[a] M. Sicignano, Dr. R. Schettini, L. Sica, G. Pierri, Prof. Dr. F. De Riccardis, Prof. Dr. I. Izzo, Dr. G. Della Sala

Dipartimento di Chimica e Biologia "Adolfo Zambelli" Università degli Studi di Salerno

Via Giovanni Paolo II 132, 84084 Fisciano, SA, Italy

E-mail: gdsala@unisa.it

[b] Dr. B. Maity, Dr. Yury Minenkov, Prof. Dr. Luigi Cavallo KAUST Catalysis Center,KCC

King Abdullah University of Science and Technology, KAUST

Thuwal 23955-6900, Saudi Arabia

E-mail: luigi.cavallo@kaust.edu.sa

Supporting information for this article is given via a link at the end of the document.((Please delete this text if not appropriate)) biological activities, neuroprotective, neurotransmitter antagonist, vasodilating, anti-platelet aggregation, anti-inflammatory, antioxidant, cytotoxic, anti-bacterial, insecticidal and nematicidal among them. ${ }^{[1,2]}$ Accordingly, the incorporation of this pharmacophore has been exploited to synthesize a number of novel pharmaceuticals and agrochemicals. ${ }^{[3]}$ In addition, phthalides proved to be valuable building blocks for the synthesis of other bioactive products and pharmaceuticals, such as anthracyclines and other anthraquinoid and naphtoquinoid compounds, isocoumarins, antidepressant phthalanes, and benzoxazinones. ${ }^{[4]}$

More than half of the approximatively 300 phthalides isolated to date are represented by 3-monosubstituted derivatives with stereogenic centers located at C-3 and/or in other positions, a major fraction of them showing interesting biological activity (Figure 1). ${ }^{[1,2]}$

The main stereoselective synthetic strategy used to prepare these compounds involves the stereocontrolled construction of the lactone ring starting from aromatic substrates, or the simultaneous formation of both rings. ${ }^{[1 a, 2,5,6]}$ An alternative and 
mostly neglected route could be the stereoselective group insertion at the C-3 site of an unsubstituted phthalide substrate. The key point of this method is the weak acidity of the phthalide C-3 that can be harnessed in reactions with electrophiles upon activation with bases. By analogy with the more popular "vinylogous synthesis", [7] this strategy may be designated as "arylogous synthesis", with reference to the propagation of electron-withdrawing effect of the carbonyl group to the lactone $Y$-position through the conjugated aromatic ring (Scheme 1a).

In a few cases organocatalytic stereoselective alkyl group $Y^{-}$ insertions of C-3 activated phthalides have been developed; however, these are not true examples of arylogous synthesis, since the C-3 position is directly activated by additional electronwithdrawing groups, such as ester or cyano functionalities, so that 3,3-disubstituted products are formed (Scheme 1b). ${ }^{[8]}$ On the other hand, reactions at the $\mathrm{y}$-site are envisaged to be more challenging with C-3 unsubstituted phthalide substrates due to their poor acidity. As a consequence C-3 unsubstituted phthalide substrates do not appear to be sufficiently activated to smoothly react with electrophiles at the $y$-site under mild base conditions. Indeed, 3-monosubstituted phthalides could been only obtained through prior deprotonation with strong bases, such as lithium amides, followed by reaction with electrophiles; unfortunately, under such harsh conditions substantial amounts of byproducts are formed and the stereochemical course of reactions could not be controlled. ${ }^{[9]}$ For instance, the anion generated by treatment of phthalide with lithium diisopropylamide, reacts with $\alpha, \beta$ unsaturated ketones affording the expected 1,4-adducts as mixture of diastereomers in low yields along with rearrangement and cyclization products, and with $\alpha, \beta$-unsaturated esters and nitriles leading exclusively to cyclization products (Scheme 1c). ${ }^{[9 a, b]}$

It is well known that the basicity of otherwise weak inorganic bases such alkali metal hydroxides could be exceptionally enhanced under phase-transfer conditions, to an extent which makes it feasible to promote reactions of extremely weak acid donor with electrophiles. ${ }^{[10]}$ Such systems combine the advantages of mild conditions, cost savings, no need of strictly dry conditions and special handling, and suitability for largescale preparations. During our ongoing research on stereoselective phase-transfer processes promoted by macrocyclic catalysts, ${ }^{[11,12]}$ we reported the first arylogous Michael addition (AMR) of the weakly activated 3-arylphthalides to various $\alpha, \beta$-unsaturated carbonyl compounds promoted by catalytic amounts of crown ethers and solid $\mathrm{KOH}$ in mesitylene (Scheme 1d). ${ }^{[13]}$ Our methodology has been recently adopted in an efficient, cost-saving and environmentally friendly integrated photo-flow oxidative protocol covering both the aryl phthalide synthesis and the AMR. ${ }^{[14]}$

The idea of applying the arylogous approach to C-3 unsubstituted substrates would appear even more intriguing given the wide occurrence of 3-monosubstituted phthalide derivatives in nature. In this paper we report the first diastereoselective AMR of unactivated phthalides promoted by inorganic base and crown ether catalysts (Scheme 1e). a) Arylogous reactions of phthalides

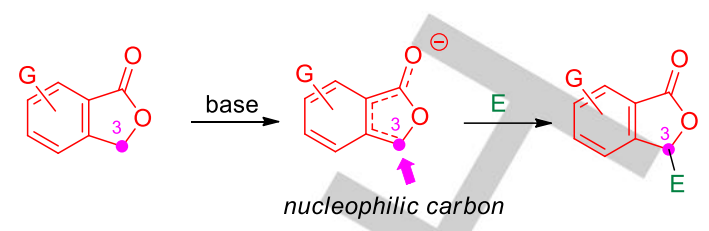

b) Previous work: Stereoselective reactions with 3-activated phthalides ${ }^{[8]}$

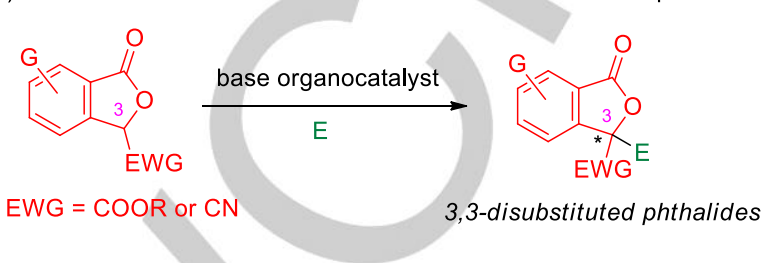

c) Previous work: Arylogous Michael reaction with strong bases ${ }^{[9 a, b]}$

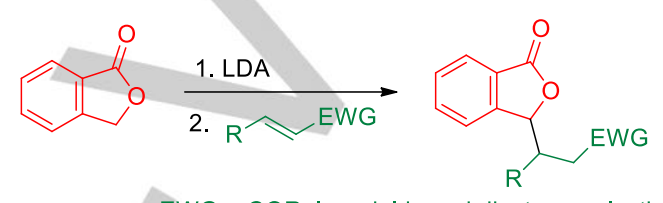

EWG $=$ COR: low yields and diastereoselectivity

EWG $=$ COOR, CN: no Michael adducts

d) Our previous work: Arylogous Michael reaction of 3-arylphthalides ${ }^{[13]}$

$$
\begin{gathered}
\text { 3,3-disubstituted phthalide } \\
\text { high diastereoselectivity } \\
\text { good yields }
\end{gathered}
$$

e) This work: Arylogous Michael reaction of unactivated phthalides

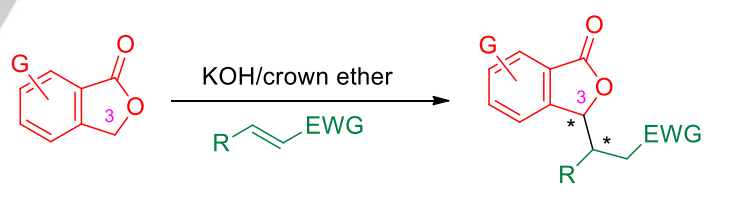

3-monosubstituted phthalides

Scheme 1. Arylogous reactions of phthalides.

\section{Results and Discussion}

\section{Development of the AMR of unactivated phthalides}

As an initial approach, we attempted to transpose reaction conditions previously optimized with 3-aryl substrates to unsubstituted phthalides. ${ }^{[13]}$ Thus, we used catalytic amounts of $\mathrm{KOH}$ and dicyclohexane-18-crown-6 (DCH18C6) to promote reaction of phthalide (1a) and trans-chalcone (2a) at room temperature in toluene (Table 1, entries 1 and 2). Only traces of the expected product 3aa were observed with $10 \mathrm{~mol} \%$ of $\mathrm{KOH}$ (entry 1) and a very low conversion was achieved with $20 \mathrm{~mol} \%$ (entry 2). An increase in the amount of $\mathrm{KOH}$ up to 1 molar equivalent enhanced the yield of 3 aa to $45 \%$ in a few hours 
(entry 3). The yield could not be improved with prolonged reaction time. In fact, a reaction follow-up by ${ }^{1} \mathrm{H}$ NMR during 24 h showed a complete disappearance of phthalide 1a after just 6 $\mathrm{h}$, with the formation of a precipitate by-product probably due to the opening of lactone ring, while conversion of chalcone 2a stopped after this time. ${ }^{[15]}$ The Michael adduct 3aa was obtained in high diastereomeric ratio (95:5). Relative configuration of the major diastereomer turned out to be syn, as determined by X-ray analysis (Figure 2). ${ }^{[16]}$ An analogous diastereo-preference has been previously reported by us in the AMR of 3-aryl phthalides. ${ }^{[13]}$ In an attempt to reduce the side reaction of phthalide, we surveyed different bases, but with poor results. Yield was very low with $t$-BuOK (entry 4 ) due to the formation of many by-products and no conversion was observed with PhOK or $\mathrm{K}_{2} \mathrm{CO}_{3}$ (entries 5,6). An experiment with stoichiometric amounts of both $\mathrm{KOH}$ and $\mathrm{DCH} 18 \mathrm{C} 6$ resulted just in a slight yield improvement but decomposition of 1a was not suppressed and it was accompanied by degradation of chalcone $\mathbf{2 a}$ and decreasing in diastereoselectivity (entry 7 ).

Table 1. Michael reaction of phthalide (1a) and trans-chalcone (2a) promoted by inorganic bases and $\mathrm{DCH} 18 \mathrm{C} 6$. $^{\text {[a] }}$

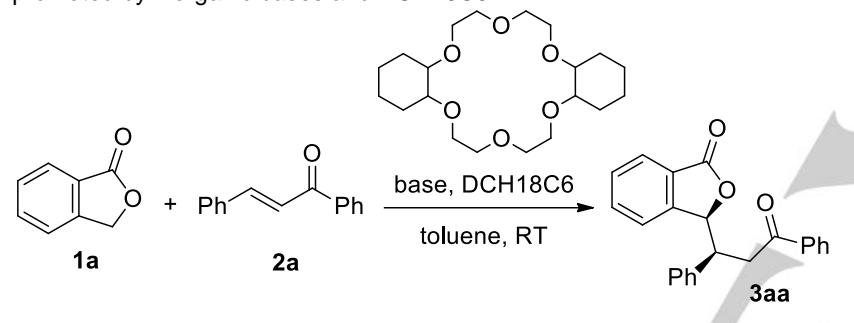

\begin{tabular}{|c|c|c|c|c|}
\hline Entry & Base [mol equiv.] & $t[\mathrm{~h}]$ & Yield [\%] $]^{[b]}$ & syn/anti[c] \\
\hline 1 & $\mathrm{KOH}[0.10]$ & 216 & traces & - \\
\hline 2 & $\mathrm{KOH}[0.20]$ & 144 & 13 & N.D. \\
\hline 3 & $\mathrm{KOH}[1.0]$ & 6 & 45 & $95: 5$ \\
\hline 4 & $t$-BuOK [1.0] & 6 & 18 & N.D. \\
\hline 5 & $\mathrm{PhOK}[1.0]$ & 96 & No reaction & N.D. \\
\hline 6 & $\mathrm{~K}_{2} \mathrm{CO}_{3}[1.0]$ & 96 & No reaction & N.D. \\
\hline $7^{[d]}$ & $\mathrm{KOH}[1.0]$ & 6 & 55 & $93: 7$ \\
\hline
\end{tabular}

[a] Reactions were performed using $1 \mathrm{a}(0.20 \mathrm{mmol}), 2 \mathrm{a}(0.20 \mathrm{mmol}), \mathrm{KOH}$ ( $\mathrm{mmol})$ and $\mathrm{DCH} 18 \mathrm{C} 6(0.020 \mathrm{mmol})$ in toluene $(1.0 \mathrm{~mL})$ unless otherwise noted. Work-up was carried out by addition of $1: 3 \mathrm{HCl} 1 \mathrm{M} / \mathrm{THF}$ mixture $(4.0$ $\mathrm{mL}$ ). [b] Yield of isolated product. [c] Determined by ${ }^{1} \mathrm{H}$ NMR analysis of the crude product mixture. [d] 1.0 molar equivalents $(0.20 \mathrm{mmol})$ of $\mathrm{DCH} 18 \mathrm{C} 6$ were used.

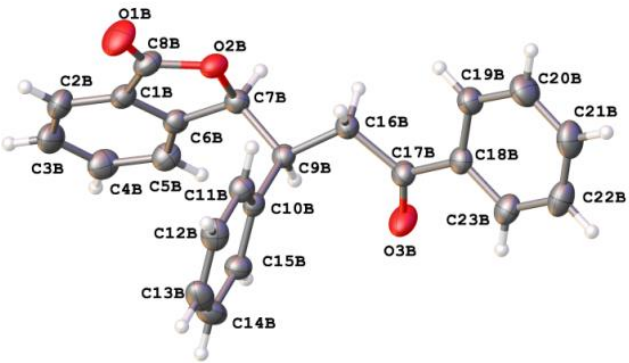

Figure 2. Single-crystal X-ray structure of 3aa. ${ }^{[16]}$

Being disappointed by the above preliminary results, we decided to make substantial changes to the reaction protocol. A recently reported vinylogous aldol reaction of $(5 H)$-furan-2-ones catalyzed by quaternary ammonium aryloxide salts, inspired us to use $\mathrm{N}, \mathrm{O}$-bis(trimethylsilyl)acetamide (BSA) as a silylating additive to trap the Michael adduct into its enolsilane form. ${ }^{[17]}$

Reaction of $1 \mathbf{a}$ and $\mathbf{2} \mathbf{a}$ with 1 equiv. of $\mathrm{KOH}$ and a small excess of BSA reached total conversion in $1 \mathrm{~h}$, but affording 3aa in moderate yield, due to the formation of several by-products and degradation of chalcone, and with the same d.r. as obtained in the absence of BSA (Table 2, entry 1). Fortunately, a radical improvement of the yield was achieved with catalytic amount of $\mathrm{KOH}(20 \mathrm{~mol} \%)$, with no significant erosion of the diastereoselectivity (entry 2). A further reduction of $\mathrm{KOH}$ amount drastically slowed down the reaction, resulting in low conversions even after long reaction time (entry 3 ). Optimization of the reaction was also achieved by changing the amount of BSA and the temperature. Higher amounts of BSA afforded 3aa in higher yield: the best compromise between yield and d.r. was reached using 1.5 equiv. of BSA (entry 4), while diastereoselectivity dropped with larger excess of silylating agent (entry 5). The yield of 3aa was progressively improved moving down from room temperature to $-40^{\circ} \mathrm{C}$, while retaining the diastereoselectivity (cf. entry 4 with entries 6-8). This may be explained by the reduction of chalcone decomposition when decreasing the temperature. In fact, exposure of $\mathbf{2 a}$ to the reaction conditions in the absence of $\mathbf{1 a}$, resulted in its total consumption within $1 \mathrm{~h}$ at room temperature, while no significant amount of degradation products was detected at $-40{ }^{\circ} \mathrm{C}$ after 2 days. ${ }^{[15]}$ However, the slowdown of reaction rate at temperatures lower than $-40{ }^{\circ} \mathrm{C}$ led to incomplete conversion and lower diastereoselectivity (entry 9,10).

Table 2. Michael reaction of phthalide (1a) and trans-chalcone (2a) with BSA catalysed by $\mathrm{KOH} / \mathrm{DCH} 18 \mathrm{C} 6$. ${ }^{[a]}$

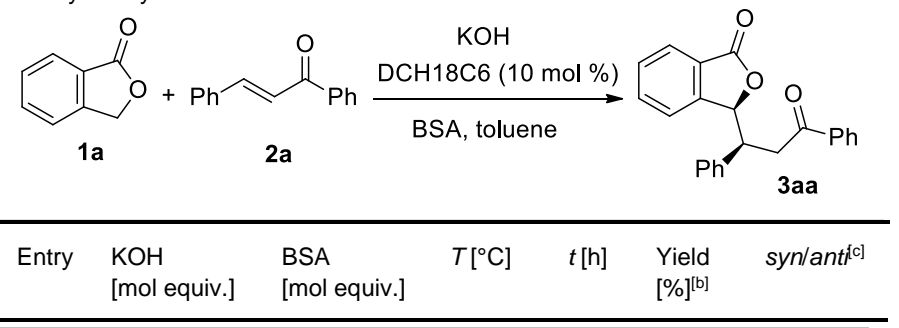




\begin{tabular}{lllllll}
\hline 1 & 1.0 & 1.2 & RT & 1 & 42 & $95: 5$ \\
2 & 0.20 & 1.2 & RT & 1 & 80 & $94: 6$ \\
3 & 0.10 & 1.2 & RT & 48 & 30 & $95: 5$ \\
4 & 0.20 & 1.5 & RT & 1 & 86 & $94: 6$ \\
5 & 0.20 & 2.0 & RT & 1 & 90 & $90: 10$ \\
6 & 0.20 & 1.5 & 0 & 1 & 93 & $94: 6$ \\
7 & 0.20 & 1.5 & -20 & 1 & 94 & $94: 6$ \\
8 & 0.20 & 1.5 & -40 & 2 & 98 & $94: 6$ \\
9 & 0.20 & 1.5 & -50 & 3 & 91 & $92: 8$ \\
10 & 0.20 & 1.5 & -78 & 15 & 87 & $90: 10$ \\
\hline
\end{tabular}

[a] Reactions were performed using 1a $(0.20 \mathrm{mmol}), 2 \mathrm{a}(0.20 \mathrm{mmol}), \mathrm{KOH}(\mathrm{x}$ $\mathrm{mmol}), \mathrm{BSA}(\mathrm{y} \mathrm{mmol})$ and $\mathrm{DCH} 18 \mathrm{C} 6(0.020 \mathrm{mmol})$ in toluene $(1.0 \mathrm{~mL})$ unless otherwise noted. Work-up was carried out by addition of $1: 3 \mathrm{HCl} 1 \mathrm{M} / \mathrm{THF}$ mixture $(4.0 \mathrm{~mL})$. [b] Yield of isolated product. [c] Determined by ${ }^{1} \mathrm{H}$ NMR analysis of the crude product mixture.

In the next stage we studied the effect of catalyst structure and solvent on the reaction outcome (Table 3). The phase-transfer agent proved to be indispensable to promote the reaction, as only traces of product were detected after $48 \mathrm{~h}$ at $-40{ }^{\circ} \mathrm{C}$ in the presence of just solid $\mathrm{KOH}$ and BSA (Table 3 , entry 2). The reaction rate with 18 -crown-6 $(18 \mathrm{C} 6)$ showed to be substantially lower than with $\mathrm{DCH} 18 \mathrm{C} 6$ at $-40{ }^{\circ} \mathrm{C}$, as expected based on the lower liposolubility of the former macrocycle,$^{[18]}$ but syn/anti ratio reached 99:1 (entry 3). An impressive effect of the crown ether ring size on the diastereoselectivity was observed; 15 -crown-5 (15C5) exhibited a catalytic activity comparable to $\mathrm{DCH} 18 \mathrm{C} 6$ but $1: 1$ syn/anti mixture was formed (entry 4). Sluggish reactions were observed using $\mathrm{NaOH}$ in place of $\mathrm{KOH}$. An incomplete conversion was achieved with $\mathrm{NaOH} / 18 \mathrm{C} 6$ at $-40{ }^{\circ} \mathrm{C}$ and the syn/anti ratio was lower than that obtained with $\mathrm{KOH} / 18 \mathrm{C} 6$ (cf. entries 5 and 3). An even more sluggish reaction was observed with $\mathrm{NaOH} / 15 \mathrm{C} 5$ : in order to achieve an adequate conversion, the reaction had to be performed at room temperature. Interestingly, a marked preference for the syn diastereomer was observed with $\mathrm{NaOH}$ in place of $\mathrm{KOH}$ (cf. entries 6 and 5). A possible rationale for this finding is discussed in the next section. A very low conversion and the formation of several byproducts was observed using $\mathrm{CsOH}$ in place of $\mathrm{KOH}$ at $-40^{\circ} \mathrm{C}$ (entry 7 ). Further phase-transfer catalysts were shown to promote the reaction. Quaternary ammonium salts afforded 3aa with a syndiastereoselectivity intermediate between $18 \mathrm{C} 6$ derivatives and 15C5. Good yield and diastereoselectivity were achieved with benzyltriethylammonium chloride (BTEAC, entry 8), whereas with more encumbered tetrabutylammonium chloride (TBAC) a longer reaction time was needed (yield and d.r. were somewhat lower, entry 9). [2.2.2]-Cryptand (crypt-222) afforded 3aa efficiently but, similarly to $15 \mathrm{C} 5$, an almost equimolar syn/anti mixture was formed (entry 10).
Very interesting findings could be obtained during solvent screening. Gratifyingly, reaction performed in mesitylene led to the formation of syn-3aa in high yield, comparable to that observed in toluene, and as a single diastereomer (entry 11). In addition, a clear relationship between d.r. and solvent dielectric constant was evident. In particular, the amount of anti diastereomer was found to increase progressively as the solvent dielectric constant increased. A moderate d.r. was observed in dichloromethane (entry 14) and an equimolar amount of syn and anti adducts were formed in acetonitrile (entry 15). The Michael addition was too sluggish in DMF at $-40{ }^{\circ} \mathrm{C}$, and proceeded slowly at room temperature giving the adduct mixture in good yield and low diastereoselectivity, with a small preference for the anti product (entry 16)

The effects of catalyst and solvent could be interpreted in the context of an intimate/loose ion pair mechanistic scenario as discussed below.

Table 3. Screening of catalysts and solvents. ${ }^{[a]}$

\begin{tabular}{|c|c|c|c|c|c|}
\hline \multirow[b]{2}{*}{ Entry } & \multirow{2}{*}{ Catalyst } & \multirow{2}{*}{ 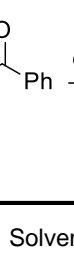 } & \multicolumn{2}{|c|}{$\begin{array}{l}\mathrm{KOH}(20 \mathrm{~mol} \%) \\
\text { catalyst }(10 \mathrm{~mol} \%) \\
\underset{\mathrm{BSA},-40{ }^{\circ} \mathrm{C}, \text { solvent }}{\longrightarrow}\end{array}$} & 3aa \\
\hline & & & $t[\mathrm{~h}]$ & Yield [\%] ${ }^{[b]}$ & syn/anti[ic] \\
\hline 1 & $\mathrm{DCH} 18 \mathrm{C} 6$ & toluene & 2 & 98 & $94: 6$ \\
\hline 2 & - & toluene & 48 & traces & - \\
\hline 3 & $18 \mathrm{C} 6$ & toluene & 15 & 97 & $99: 1$ \\
\hline 4 & $15 \mathrm{C} 5$ & toluene & 2 & 90 & $50: 50$ \\
\hline $5^{[d]}$ & $18 \mathrm{C} 6$ & toluene & 168 & 71 & $94: 6$ \\
\hline $6^{[\mathrm{d}, \mathrm{e}]}$ & $15 \mathrm{C} 5$ & toluene & 48 & 86 & $80: 20$ \\
\hline $7^{[f]}$ & $18 \mathrm{C} 6$ & toluene & 144 & 6 & $80: 20$ \\
\hline 8 & BTEAC & toluene & 4 & 87 & $92: 8$ \\
\hline 9 & TBAC & toluene & 48 & 69 & $88: 12$ \\
\hline 10 & crypt-222 & toluene & 7 & 87 & $55: 45$ \\
\hline 11 & $18 \mathrm{C} 6$ & mesitylene & 15 & 96 & $>99: 1$ \\
\hline 12 & $18 \mathrm{C} 6$ & $\mathrm{Et}_{2} \mathrm{O}$ & 2 & 89 & $97: 3$ \\
\hline 13 & $18 \mathrm{C} 6$ & THF & 2 & 90 & $88: 12$ \\
\hline 14 & $18 \mathrm{C} 6$ & DCM & 1 & 88 & $69: 12$ \\
\hline 15 & $18 \mathrm{C} 6$ & $\mathrm{ACN}$ & 8 & 71 & $50: 50$ \\
\hline $16^{[\mathrm{e}]}$ & $18 \mathrm{C} 6$ & DMF & 48 & 72 & $43: 57$ \\
\hline
\end{tabular}

[a] Reactions were performed using 1 a $(0.20 \mathrm{mmol}), \mathbf{2 a}(0.20 \mathrm{mmol}), \mathrm{KOH}$ $(0.040 \mathrm{mmol}), \mathrm{BSA}(0.30 \mathrm{mmol})$ and catalyst $(0.020 \mathrm{mmol})$ in the appropriate solvent $(1.0 \mathrm{~mL})$ at $-40{ }^{\circ} \mathrm{C}$ unless otherwise noted. Work-up was carried out by addition of $1: 3 \mathrm{HCl} 1 \mathrm{M} / \mathrm{THF}$ mixture $(4.0 \mathrm{~mL})$. [b] Yield of isolated product. [c] Determined by ${ }^{1} \mathrm{H}$ NMR analysis of the crude product mixture. [d] 
$\mathrm{NaOH}(0.040 \mathrm{mmol})$ was used in place of $\mathrm{KOH}$. [e] Reaction was performed at room temperature. [f] $\mathrm{CsOH}(0.040 \mathrm{mmol})$ was used in place of $\mathrm{KOH}$.

With the optimized reaction conditions in hand we studied the scope of the AMR with diversely substituted phthalides and $\alpha, \beta$ unsaturated carbonyl compounds (Table 4). However, the wide range of reactivity observed for different substrates required a reassessment of the optimal reaction temperature for each case. We first evaluated the reaction of unsubstituted phthalide 1a with variously functionalized trans-chalcones $\mathbf{2 b}$-j. Total conversions and high yields were achieved after $15 \mathrm{~h}$ at $-40{ }^{\circ} \mathrm{C}$ with chalcones containing electron-donating groups on either aromatic ring (products 3ab, 3ac, 3ah and 3ai), as well as with heteroaromatic substrates $\mathbf{2 f , g}$ containing a 2-furanyl and a 2thiophenyl group respectively (products 3 af and $3 \mathrm{ag}$ ). A similar reactivity was also displayed by $p$-fluorosubstituted derivative $\mathbf{2 d}$ (product 3ad). Longer reaction times were needed with other electronpoor chalcones such as $\mathbf{2 e}$ and $\mathbf{2} \mathbf{j}$; in the former case a low yield was obtained (product $\mathbf{3 a e}$ ), whereas in the latter reaction had to be performed at $0{ }^{\circ} \mathrm{C}$ (3aj). However, high to excellent d.r. (from 94:6 to >99:1) were achieved with all the chalcones regardless the electronic substituent effect. The syn relative configuration was confirmed for adduct 3 ad by X-ray diffractometric analysis. ${ }^{[19]}$

Aromatic enones $\mathbf{2 k}, \mathbf{l}$ (products $\mathbf{3} \mathbf{a k}$ and $\mathbf{3 a l}$ ) and aliphatic substrate $\mathbf{2 m}$ (product $\mathbf{3 a m}$ ) proved to be less reactive and required higher temperature and longer reaction time. However, both yields and d.r. were good to excellent, expecially for 3ak that was isolated in nearly quantitative yield and as a single diastereomer. Surprisingly, also cinnamic ester $\mathbf{2 n}$ showed to be a suitable substrate for this process, affording adduct 3an in good yield and as a single diastereomer at $-40^{\circ} \mathrm{C}$, although with long reaction time. The relative configuration of 3 an was determined by X-ray analysis and turned out to be syn as well. ${ }^{[20]}$ As far as we know, this is the first example of Michael addition of a 3 -unsubstituted phthalide to an $\alpha, \beta$-unsaturated ester. Addition to the $\mathrm{N}$-cinnamoyl-2-oxazolidinone $\mathbf{2 0}$ proved to be sluggish and required the use of the more active catalyst $\mathrm{DCH} 18 \mathrm{C} 6$ to gain acceptable yields.

Next we studied the effect of substituents on the aromatic phthalide ring. Either electronwithdrawing or electrondonating groups at C-6 and C-5 positions were well-tolerated in the AMR, albeit with some reduction of reactivity compared with the parent compound 1a, requiring longer reaction times and higher temperatures. 6-Nitro derivative $\mathbf{1 b}$ reacted with $\mathbf{2 a}$ at room temperature affording adduct 3 ba with good yield and diastereoselectivity. Moderate yield and high d.r. were obtained in the reaction of 6-methoxy derivative $1 \mathbf{c}$ with $\mathbf{2 a}$ (product $\mathbf{3 c a}$ ). On the other hand, high yields and excellent diastereoselectivities were achieved with both 5-methoxy and 5trifluoromethyl phthalide at $-20^{\circ} \mathrm{C}$ (products $3 \mathrm{da}$ and $3 \mathrm{ea}$ ).

After completion of this study, in order to assess the full potential of our methodology, we wondered whether it could also be applied to unactivated 3-alkyl phthalides to achieve the diastereoselective synthesis of 3,3-dialkyl phthalides. In that regard, it is worth noting that no arylogous reactions with 3-alkyl phthalides has been reported so far in the literature. To our delight, 3-ethylphthalide (1f) reacted completely with $\mathbf{2 a}$ at room temperature in just $3 \mathrm{~h}$ affording the expected adduct 3 fa with high yield and d.r. (Scheme 2). The same diastereoselectivity and an even higher yield was achieved at $-20{ }^{\circ} \mathrm{C}$, but with longer reaction times.

Table 4. Scope of the AMR of unactivated phthalides. ${ }^{[a-c]}$

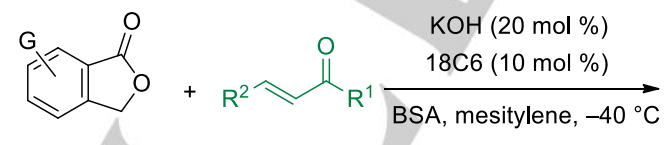

1

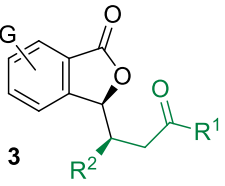


<smiles>O=C(CC(c1ccccc1)c1ccccc1)OC1OC(=O)c2ccccc21</smiles>

3aa, 15 h, $96 \%$, >99:1 d.r.<smiles>O=C(CC(c1ccc(C(F)(F)F)cc1)C1OC(=O)c2ccccc21)c1ccccc1</smiles>

3ae, 168 h, $25 \%$, 96:4 d.r.<smiles>O=C(C[C@H](c1ccccc1)[C@H]1OC(=O)c2ccccc21)c1ccc(Cl)cc1</smiles>

3aj, $0{ }^{\circ} \mathrm{C}, 72$ h, $94 \%, 96: 4$ d.r.<smiles>O=C1O[C@H]([C@H](CC(=O)N2CCOC2=O)c2ccccc2)c2ccccc21</smiles>

3ao, 120 h, $42 \%$, >99:1 d.r. [d]

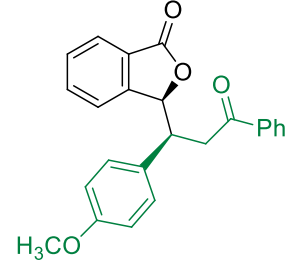

3ab, 15 h, $96 \%$, >99:1 d.r

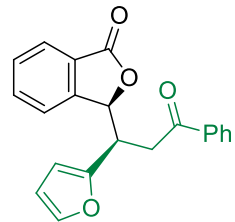

3af, 15 h, $98 \%, 96: 4$ d.r.

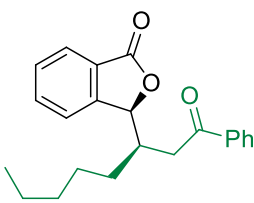

3ak, $0{ }^{\circ} \mathrm{C}, 168 \mathrm{~h}$ $98 \%,>99: 1 \mathrm{~d} . r$.
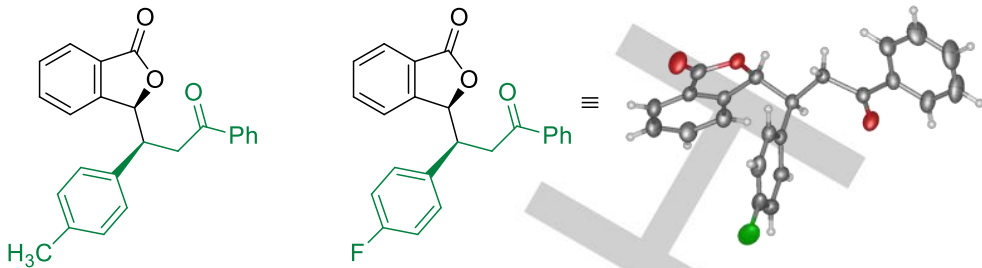

3ac, 15 h, $98 \%$, 90:10 d.r.

3ad, 15 h, $89 \%$, >99:1 d.r. (CCDC 1874897 $)^{[18]}$<smiles>O=C(C[C@H](c1cccs1)[C@H]1OC(=O)c2ccccc21)c1ccccc1</smiles><smiles>COc1ccc(C(=O)CC(c2ccccc2)[C@H]2OC(=O)c3ccccc32)cc1</smiles><smiles>Cc1ccc(C(=O)CC(c2ccccc2)[C@H]2OC(=O)c3c(C)cccc32)cc1</smiles>

3ag, 15 h, $76 \%$, 97:3 d.r. $\quad 3 a h, 15$ h, $97 \%$, >99:1 d.r.

3ai, 15 h, $97 \%$, 97:3 d.r<smiles>CCCC[C@H](CC)[C@H]1OC(=O)c2ccccc21</smiles>

3am, RT, $168 \mathrm{~h}$, $90 \%, 86: 14$ d.r.

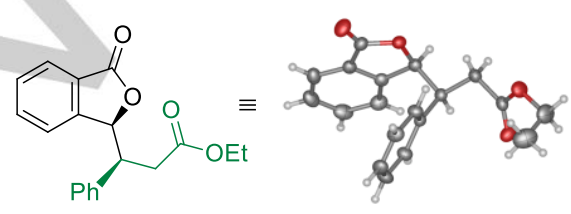

3an, 168 h, $78 \%$, >99:1 d.r. $\left(\right.$ CCDC 1874897) ${ }^{[19]}$
$3 a \mathrm{al}, 0{ }^{\circ} \mathrm{C}, 168 \mathrm{~h}$ $73 \%, 88: 12$ d.r.<smiles>O=C(C[C@H](c1ccccc1)[C@H]1OC(=O)c2cc([N+](=O)[O-])ccc21)c1ccccc1</smiles>

3ba, RT, $72 \mathrm{~h}$, $87 \%, 84.16 \mathrm{~d} r$

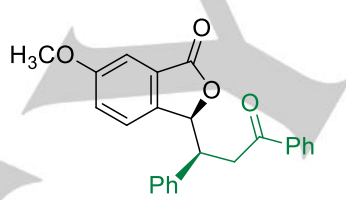

$3 \mathbf{c a}, 0^{\circ} \mathrm{C}, 168 \mathrm{~h}$, $49 \%, 96: 4$ dr.<smiles>COc1ccc2c(c1)[C@H]([C@H](CC(=O)c1ccccc1)c1ccccc1)OC2=O</smiles>

$3 \mathrm{da},-20^{\circ} \mathrm{C}, 15 \mathrm{~h}$, $93 \%, 99: 1$ d.r.<smiles>O=C(CC(c1ccccc1)c1ccccc1)OC1C(=O)Oc2ccccc21</smiles>

3ea, $-20^{\circ} \mathrm{C}, 72 \mathrm{~h}$ $88 \%,>99: 1$ d.r.

[a] Reactions were performed using $1(0.20 \mathrm{mmol}), 2(0.20 \mathrm{mmol}), \mathrm{KOH}(0.040 \mathrm{mmol}), \mathrm{BSA}(0.30 \mathrm{mmol})$ and $18 \mathrm{C} 6(0.020 \mathrm{mmol})$ in mesitylene $(1.0 \mathrm{~mL})$ at $-40{ }^{\circ} \mathrm{C}$ unless otherwise noted. Work-up was carried out by addition of $1: 3 \mathrm{HCl} 1 \mathrm{M} / \mathrm{THF}$ mixture $(4.0 \mathrm{~mL})$. [b] Yield of isolated product. [c] Diastereomeric ratios were determined by ${ }^{1} \mathrm{H}$ NMR analysis of the crude product mixture. [d] $\mathrm{DCH} 18 \mathrm{C} 6(0.020 \mathrm{mmol})$ was used in place of $18 \mathrm{C} 6$.

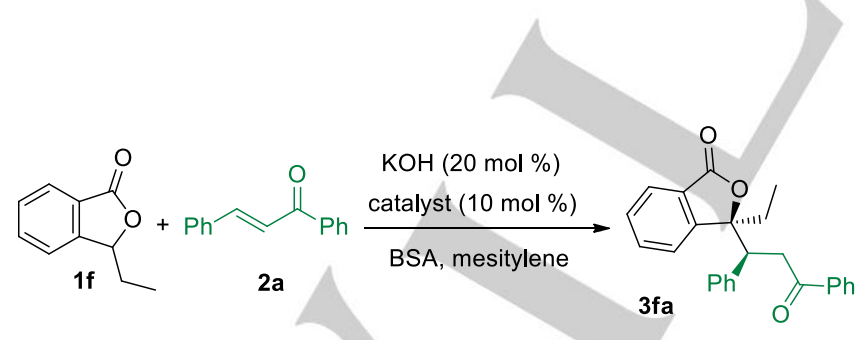

RT, 3 h, $85 \%$ yield, $97: 3$ d.r.

$-20{ }^{\circ} \mathrm{C}, 168 \mathrm{~h}, 91 \%$ yield, $97: 3$ d.r.

Scheme 2. AMR of 3-ethylphthalide catalysed by $\mathrm{KOH} / 18 \mathrm{C} 6$.

\section{Mechanistic insights and DFT calculations}

With the aim of gaining insights into the origin of diastereocontrol in our AMR of phthalides, we started with assuming a plausible mechanism. It has been previously demonstrated that BSA could be desilylated by catalytic amounts of Lewis base salts affording amide salts that can be used to deprotonate carbon acids in order to promote their reactions with electrophiles. ${ }^{[17,21]}$ In a closely related transformation, catalytic amounts of alkali metal aryloxides and stoichiometric amounts of BSA in the presence of phase transfer catalysts have been used to promote the vinylogous aldol addition of $y$-butenolides. The intermediate formation of an onium amide base able to deprotonate the $y$ lactone generating a nucleophilic onium dienolate ion pair has been suggested. ${ }^{[17]}$ By analogy, we postulated the mechanism depicted in Scheme 3. The $\mathrm{K}^{+} \subset$ crown amide ion pair 4, generated by desilylation of BSA with the $\mathrm{KOH}$-crown complex, would deprotonate the substrate giving rise to a $\mathrm{K}^{+} \subset$ crown/phthalide anion ion pair 5 that carries out the nucleophilic addition to the Michael acceptor. The resulting anion adduct would be silylated by BSA regenerating 4 and affording $\mathbf{6}$. The latter product is generally decomposed under acidic work-up which delivers products 3 . In accordance with that scenario, phase-transfer catalysts other than crown ethers, 
such as quaternary ammonium salts and cryptands, are capable of promoting this reaction (Table 3 , entry 8-10) through the intermediate formation of reactive ion pairs similar to $\mathbf{5}$. In addition, when acidic work-up was avoided, the silylated adduct $\mathbf{6} \mathbf{a}$ a could be isolated in high yields from reaction of $\mathbf{1 a}$ with $\mathbf{2} \mathbf{a}$, corroborating the above mechanism. ${ }^{[22]}$ A major advantage of such reaction conditions is that the ready consumption of hydroxide ion in the initiation step prevents lactone opening.

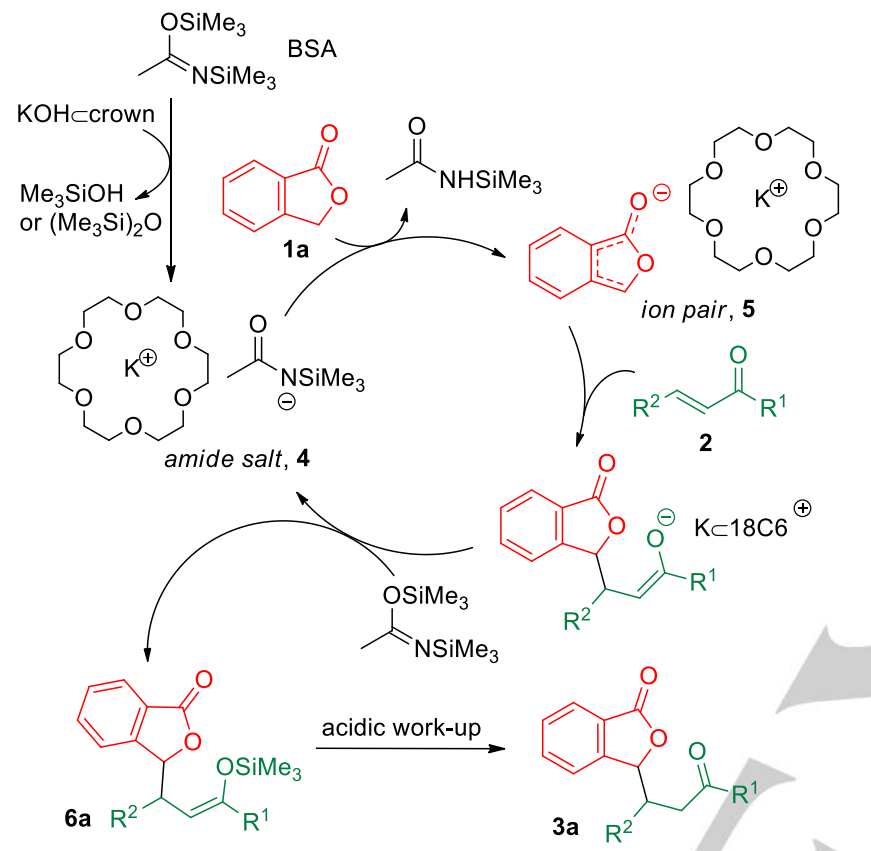

Scheme 3. Postulated mechanism of the AMR catalysed by $\mathrm{KOH} / 18 \mathrm{C} 6$ in the presence of BSA.

A key issue to be addressed was whether the formation of addition products occurs under kinetic or thermodynamic control. To this end, we submitted 3aa as a 50:50 syn-anti mixture (previously obtained in entry 15 , Table 3 ) to the usual reaction conditions in the presence of catalytic amounts of $\mathrm{KOH} / 18 \mathrm{C} 6$ and stoichiometric amounts of BSA in toluene at $-40{ }^{\circ} \mathrm{C}$. After $24 \mathrm{~h}$ we isolated a mixture with only marginally altered d.r. (53:47 syn/anti). ${ }^{[23]}$ Considering that 3aa was obtained as a 99:1 syn/anti mixture from reaction of $2 \mathbf{a}$ with $3 \mathbf{a}$ under the same conditions in $15 \mathrm{~h}$ (Table 3 , entry 3 ), it could be argued that the Michael addition is substantially irreversible and the syndiastereoselectivity mainly arises from kinetic control.

Consequently, we decided to carry out a DFT study of the transition state, bearing in mind that a suitable model must be in agreement with the observed dependence of the syn/anti ratio on both the solvent dielectric constant and the type of phasetransfer catalyst. In a previous study of the vinylogous Mukaiyama-Michael reaction (VMMR) of trimethylsilyloxyfuran with $\alpha, \beta$-unsaturated ketones we already observed the diastereoselectivity to be strongly dependent on the solvent and the catalyst used. ${ }^{[12]}$ In particular a high syn-diastereoselectivity was achieved with KF and $18 \mathrm{C} 6$ derivatives in a non-polar solvent such as toluene, whereas the anti diastereomer prevailed in polar solvents. DFT calculations demonstrated that such switchable diastereoselectivity is the result of different degrees of ion separation in the dienolate anion/counterion ion pair involved in the addition step. ${ }^{[24]}$ In low dielectric constant solvents a contact ion pair could be assumed, and the synadduct results from a exo chelated transition state in which the cation is coordinated both to the dienolate and to the Michael acceptor. On the other hand, solvents with higher dielectric constant would lead to more solvent separated ion pairs so that the cation assistance can be neglected. The endo approach of the reactants, affording the anti-product, resulted to be favored under such cation-free conditions. In addition, when the reaction was promoted by 15 -crown-5 derivatives, crypt-222 or TBAF instead of $18 \mathrm{C} 6$ derivatives, the anti product prevailed even in toluene. In fact, while the cation center of $\mathrm{K}^{+} \subset 18 \mathrm{C} 6$ derivatives complexes is sterically accessible from the open faces of the ring plane enabling a tight anion-cation contact, with more shielded cations center of bulky quaternary ammonium, cryptate $\mathrm{K}^{+} \subset$ crypt-222 complex and sandwich $\mathrm{K}^{+} \subset 15 \mathrm{C} 5$ complexes, ion pairing is weaker. ${ }^{[25]}$

Given the parallels between the assumed mechanisms and the structures of butenolide and phthalides, a similar behavior was expected also for this arylogous reaction. Data reported in table 3 fully confirmed such a prediction, since excellent synselectivities were obtained with $\mathrm{KOH}$ and $18 \mathrm{C} 6$ derivatives in non-polar solvents such as toluene and mesitylene, while a progressive increment of the anti-product amount was observed as the medium dielectric constant increased (cf. entries 3 and 11-16 in Table 3). Our working hypothesis was that in non-polar solvents a tight ion pair is involved, in which the cation assists the formation of the syn-product. Conversely, the participation of the cation is no longer possible in more polar media, in which solvent separated ion pairs dominate, bringing to lower diastereomeric ratios.

In order to elucidate the observed syn/anti-diastereoselectivity under different reaction conditions, DFT calculations were performed at M06-2X(SMD)/TZVPD//B3LYP/SVP level of theory for the reaction of phthalide (1a) anion with trans-chalcone (2a). ${ }^{[26]}$ For the reaction in non-polar solvents, involving the tight ion pair 5, two different Diels-Alder-like transition states were modeled, with cation $\mathrm{K}^{+} \subset 18 \mathrm{C} 6$ in close proximity, leading to synand anti-products respectively (Figure $3 \mathrm{a}$ ). Relative energies reveal that the transition state exo-TS-A is preferred affording the syn-adduct, over the competing transition state endo-TS-A, $6.6 \mathrm{kcal} / \mathrm{mol}$ higher in energy. Such energy gap is in agreement with the high syn-diastereoselectivity experimentally observed. The preference of exo- attack is ascribed to the simultaneous electrostatic attraction of the two negatively charged oxygen (red color in Figure $3 \mathrm{a}$ ) of the reactants with $\mathrm{K}^{+}$. The DFT analysis was also performed with $\mathrm{DCH} 18 \mathrm{C} 6$ in place of $18 \mathrm{C} 6$ in toluene (exo-TS-B and endo-TS-B in Figure 3b). The preference for the exo approach was good, although lower than observed with the parent crown ether $\left(\Delta \Delta \mathrm{G}^{\ddagger}=3.6 \mathrm{kcal} / \mathrm{mol}\right)$, in fairly good agreement with the relative diastereoselectivity experimentally observed with the two macrocycles (cf. entries 1 and 3 in Table 3). In order to get more insights on the higher 
diastereoselectivity of $18 \mathrm{C} 6$ compared to DCH18C6, we performed an energy decomposition analysis (EDA), by fragmenting the systems into the $\mathrm{K}^{+} \subset$ crown complexes and the organic substrates. The EDA revealed that the higher exo preference with $18 \mathrm{C} 6$ is essentially due to the steric hindrance of $\mathrm{DCH} 18 \mathrm{C} 6$. The presence of bulky cyclohexane rings requires an higher energy cost to deform the macrocycle and accommodate the reacting molecules into the exo transition state, and also entails a lower interaction energy with phthalide anion and chalcone. ${ }^{[27]}$

Afterwards, to simulate the involvement of a separated ion pair in polar solvents (e.g. DMF), the exo and endo attack of the "naked" phthalide anion to trans-chalcone were modeled (exoTS-C and endo-TS-C in Figure 3c). Transition states endo-TS-C and exo-TS-C resulted to be very similar in energy $\left(\Delta \Delta G^{\ddagger}=0.4\right.$ $\mathrm{kcal} / \mathrm{mol}$, in favour of the endo approach). This is in good agreement with the experimental observations since the two diastereomeric products 3aa were formed in almost equal quantity in DMF, with a small preference for the anti adduct
(Table 3, entry 16). Such model could also explain the catalyst's structure effect. If the steric accessibility of the cation is poor, ion pair 5 cannot be tight enough to enable a cation-directed exo approach. Accordingly, KOH/crypt222 and KOH/15C5 catalytic systems, giving rise to a cryptate and a sandwich complex respectively with a poorly accessible $\mathrm{K}^{+}$cation, furnished extremely low d.r., comparable to that achieved in very polar solvents (entry 10 and 4, Table 3). As a further evidence supporting this hypothesis, reaction promoted by $\mathrm{NaOH} / 15 \mathrm{C} 5$ displayed a much better syn-diastereoselectivity, as a result of a greater steric accessibility of $\mathrm{Na}^{+} \subset 15 \mathrm{C} 5$ (entry 6, Table 3). In good agreement with the intermediate steric accessibility between cryptates and $\mathrm{K}^{+} \subset 18 \mathrm{C} 6$ derivatives complexes postulated for tetraalkyl ammonium cations, ${ }^{[25]}$ BTEAC and TBAC afforded good syn-diastereoselectivities although lower than $\mathrm{KOH} / 18 \mathrm{C} 6$ and $\mathrm{KOH} / \mathrm{DCH} 18 \mathrm{C} 6$ (entry 8 and 9, Table 3). As expected, diastereoselectivity was slightly higher with BTEAC than with TBAC, due to the shorter alkyl chain in the former ammonium cation. 
a) Attack of phthalide anion as a tight ion pair with $\mathrm{K}^{+} \subset 18 \mathrm{C} 6$ in toluene

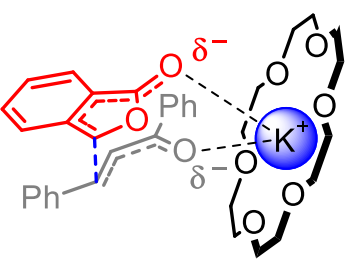

exo-TS-A

$(0.0 \mathrm{kcal} / \mathrm{mol})$

leading to syn-3aa

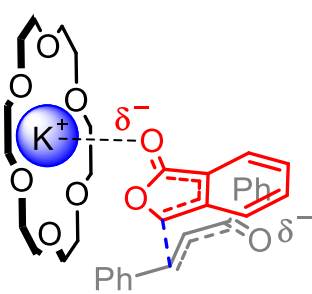

endo-TS-A

$(6.6 \mathrm{kcal} / \mathrm{mol})$

leading to anti-3aa

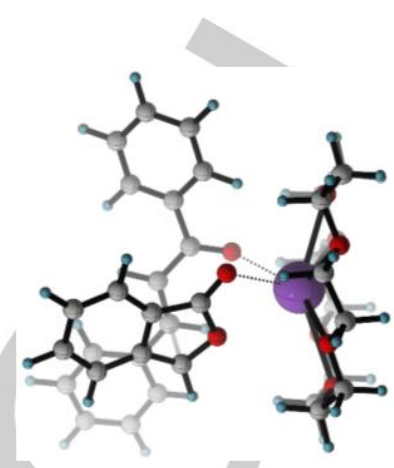

exo-TS-A

b) Attack of phthalide anion as a tight ion pair with $\mathrm{K}^{+} \subset \mathrm{DCH} 18 \mathrm{C} 6$ in toluene

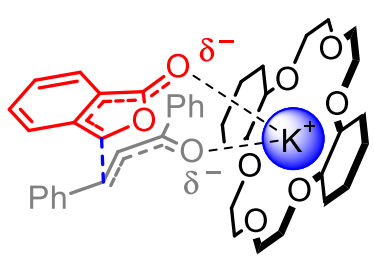

exo-TS-B

$(0.0 \mathrm{kcal} / \mathrm{mol})$ leading to syn-3aa

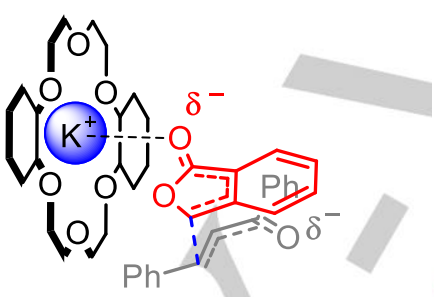

endo-TS-B

(3.6 kcal $/ \mathrm{mol})$

leading to anti-3aa

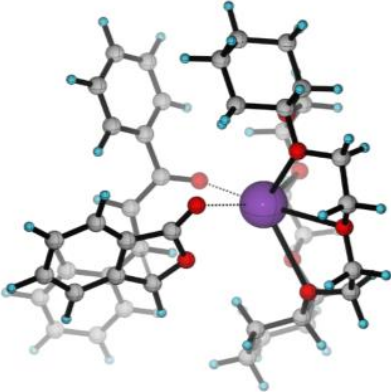

exo-TS-B

c) Attack of "naked" phthalide anion in DMF

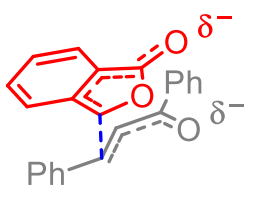

exo-TS-C

$(0.4 \mathrm{kcal} / \mathrm{mol})$ leading to syn-3aa
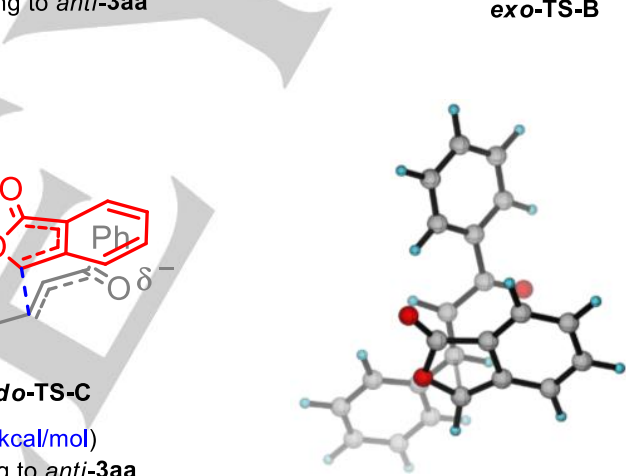

endo-TS-C

Figure 3. DFT calculations of exo and endo transition states for the AMR of phthalide anion with trans-chalcone, under cation-free or tight ion pair conditions. Values in parenthesis represents Gibbs free energy at M06-2X(SMD)/TZVPD//B3LYP/SVP level of theory.

Rather interesting considerations can also be made by comparing the solvent (or catalyst) dependent diastereoselectivity in the AMR of phthalides with that previously observed by us in the VMMR of structurally related butenolides. ${ }^{[12]}$ The VMR of butenolides displays a striking switchable diastereoselectivity, with high syn preference in nonpolar solvents and DCH18C6 as the catalyst, and high anti preference in polar solvents or in the presence of catalysts associated to poorly accessible cations. Similar trends can be found for the AMR, although a high diastereoselectivity can only be achieved for the syn product, carrying out the reaction with 18C6 derivatives in non-polar solvents. Polar solvents and poorly accessible cations, in fact, resulted in low anti-syn ratios, with just a minor preponderance of anti product. Although a DFT analysis of the switchable VMR of butenolides has been already reported by us, ${ }^{[12]}$ in this work we re-calculated the energies of exo and endo Diels-Alder like transition states of butenolide anion with trans-chalcone, either in the presence or absence of $\mathrm{K}^{+} \subset \mathrm{DCH} 18 \mathrm{C} 6$. For a better comparison with the AMR transition states (Figure 4) we used the same computational method described above for phthalide anion. In accordance with the experimental data, the exo approach (exo-TS-D in Figure 4a) resulted to be strongly favored for the tight ion pair in toluene, by virtue of the chelation effect, whereas the exo approach turned out to be far more stable for the "naked dienolate" in DMF (endo-TS-E in Figure 4b). The poor anti-diastereoselectivity 
achieved in the AMR stems from the little stabilization of endoTS-C compared to the corresponding exo approach, as opposed to the strong stabilization of endo-TS-E compared to exo-TS-E. In fact, whilst exo-TS-C is destabilized by the electrostatic repulsion of the two negatively charged oxygen atoms of the reactants, endo-TS-C is destabilized by repulsive interaction between $\pi$-electrons of aromatic phthalide ring and the developing negative charge on chalcone oxygen atom.

a) Attack of butenolide anion as a tight ion pair with $\mathrm{K}^{+} \subset \mathrm{DCH} 18 \mathrm{C} 6$ in toluene

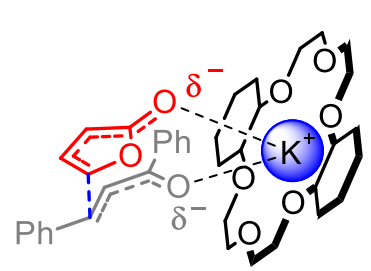

exo-TS-D

$(0.0 \mathrm{kcal} / \mathrm{mol})$

leading to syn product

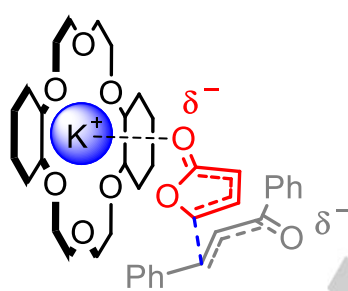

endo-TS-D

$(5.2 \mathrm{kcal} / \mathrm{mol})$

leading to anti product

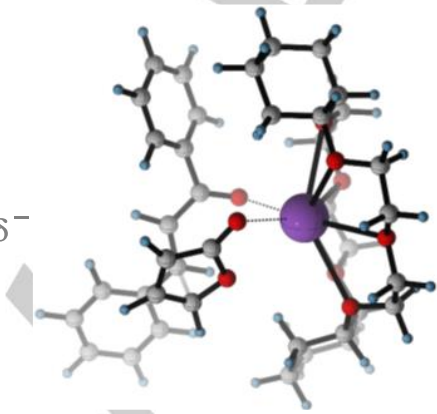

exo-TS-D

b) Attack of "naked" butenolide anion in DMF

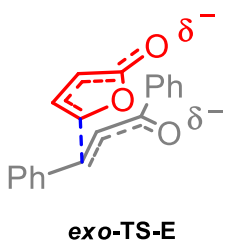

$(2.6 \mathrm{kcal} / \mathrm{mol})$

leading to syn product

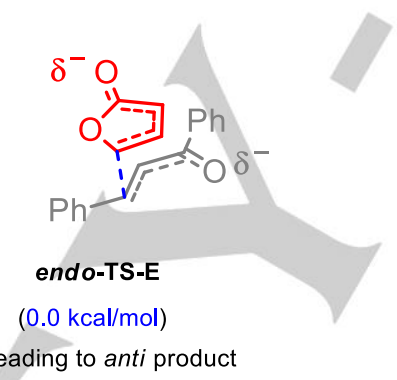

leading to anti product

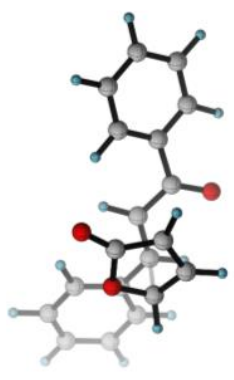

endo-TS-E

Figure 4. DFT calculations of exo and endo transition states for the VMR of butenolide anion with trans-chalcone, under cation-free or tight ion pair conditions. Values in parenthesis represents Gibbs free energy in the specified implicit solvent medium.

\section{Conclusions}

In conclusion, we have developed the first highly diastereoselective arylogous Michael reaction (AMR) of 3unsubstituted phthalides, by using mild reaction conditions and catalytic amounts of commercial readily available 18-crown-6. This method has been demonstrated to be an effective and original tool to give access to 3-alkylated phthalides, a structural motif widely distributed in bioactive natural products. Good to high yields and good to excellent syn-diastereoselectivities were achieved with a wide range of aromatic as well as aliphatic $\alpha, \beta$ unsaturated carbonyl compounds. Substitution of the phthalide aromatic ring was well tolerated. In addition, satisfactory yield and diastereoselectivity attained in the AMR of 3-ethyl phthalide proved that the method can also be applied for the synthesis of 3,3-dialkyl phthalides.

Mechanistic studies and DFT analysis of transition states have been also reported, providing a rationale for the stereoselectivity observed.
This method is well-suited for large-scale applications, given the availability of components, simple experimental procedure and low cost and environmental impact. Moreover, the principle of arylogous activation of phthalides lends itself to potential interesting advances, such as applications in enantioselective synthesis, that will be the subject of forthcoming studies by our group.

\section{Experimental Section}

\section{General procedure for the ARM of unactivated phthalides}

To a stirred solution of the $\alpha, \beta$-unsaturated carbonyl compound $2(0.20$ $\mathrm{mmol}), 18$-crown-6 (18C6, $5.3 \mathrm{mg}, 0.02 \mathrm{mmol})$ and $\mathrm{KOH}(2.2 \mathrm{mg}, 0.04$ $\mathrm{mmol}$ ) in mesitylene $(1.0 \mathrm{~mL}$ ) at the appropriate temperature (see Table 4), phthalide $1(0.20 \mathrm{mmol})$ and $\mathrm{N}, \mathrm{O}$-bis(trimethylsilyl)acetamide (BSA $61.0 \mathrm{mg}, 0.30 \mathrm{mmol}$ ) were added. The mixture was stirred at the same temperature until disappearance of the starting material (TLC), then treated with $1 \mathrm{M} \mathrm{HCl}(1.0 \mathrm{~mL})$ and THF $(3.0 \mathrm{~mL})$ and stirred at room temperature for $2 \mathrm{~h}$. The resulting mixture was diluted with $\mathrm{H}_{2} \mathrm{O}(1.0 \mathrm{~mL})$ and extracted with $\mathrm{CH}_{2} \mathrm{Cl}_{2}(3 \times 3 \mathrm{~mL})$. The combined organic phases 
were dried over $\mathrm{Na}_{2} \mathrm{SO}_{4}$ and concentrated in vacuo. The crude residue was purified by flash cromatography (silica gel, toluene) to afford 3 .

\section{Computational details}

All the transition states were optimized with the hybrid DFT functional by means of Becke's three-parameter exchange functional ${ }^{[28]}$ in addition with Lee, Yang and Parr correlation functional[29] B3LYP implemented in Gaussian 09 program packages. ${ }^{[30]}$ The electronic configuration of all the atoms were described with the Aldrich's split-valence polarization basis set SVP. ${ }^{[31]}$ All transition states were located using the linear synchronous transit (LST) method in which the reaction coordinate was kept fixed at different distances while all other degrees of freedom were relaxed. After the linear transit search the transition states were optimized using the default Berny algorithm implemented in the Gaussian09 code. ${ }^{[30]}$ For further validation of energetics, single-point calculations were performed on the B3LYP/SVP optimized geometries employing a valence triple-z-type of basis set with diffuse functions (TZVPD) ${ }^{[32]}$ using empirical dispersion corrected functional M06-2X. ${ }^{[33]} \mathrm{An}$ implicit solvation effects (Toluene, $\varepsilon=2.37$; DMF, $\varepsilon=37.22$ ) were estimated by the Minnesota solvation model (SMD). ${ }^{[34]}$ The $\Delta G$ value was obtained by augmenting the $\Delta E_{S}$ energy terms at M06-2X(SMD)/TZVPD with the respective free energy corrections at the B3LYP/SVP level. The $\Delta G$ was used throughout the text.

\section{Acknowledgements}

Financial support was provided from the University of Salerno (FARB). The computing resources used within this project have been provided by CRESCO/ENEAGRID High Performance Computing infrastructure and its staff. We thank $\mathrm{Dr}$ Patrizia lannece for HR-ESI-MS

\section{Keywords: keyword $1 \bullet$ keyword $2 \cdot$ keyword $3 \cdot$ keyword 4 •} keyword 5

[1] a) A. León, M. Del-Ángel, J. L. Ávila, G. Delgado in Progress in the Chemistry of Organic Natural Products, Vol. 104 (Eds.: A. D. Kinghorn H. Falk, S. Gibbons, J. Kobayashi), Springer, Cham, 2017, pp. 127246 ; b) G. Lin, S. S.-K. Chan, H.-S. Chung, S.-L. Li in Studies in Natural Products Chemistry: Bioactive Natural Products, Vol. 32, Part L (Ed Atta-ur-Rahman), Elsevier, Amsterdam, 2005, pp. 611-669; c) J. J. Beck, S.-C. Chou, J. Nat. Prod. 2007, 70, 891-900.

[2] R. Karmakar, P. Pahari, D. Mal, Chem. Rev. 2014, 114, 6213-6284.

[3] For selected examples see: a) A. León, J. A. Cogordán, O. Sterner, G. Delgado, J. Nat. Prod. 2012, 75, 859-864; b) J. W. Lampe, C. K. Biggers, J. M. Defauw, R. J. Foglesong, S. E. Hall, J. M. Heerding, S. P Hollinshead, H. Hu, P. F. Hughes, G. E. Jagdmann, Jr., M. G. Johnson, Y.-S. Lai, C. T. Lowden, M. P. Lynch, J. S. Mendoza, M. M. Murphy, J. W. Wilson, L. M. Ballas, K. Carter, J. W. Darges, J. E. Davis, F. R. Hubbard, M. L. Stamper, J. Med. Chem. 2002, 45, 2624-2643; c) A. F. da Silva Maia, R. P. Siqueira, F. M. de Oliveira, J. G. Ferreira, S. F. da Silva, C. A. D. Caiuby, L. L. de Oliveira, S. O. de Paula, R. A. C. Souza, S. Guilard, G. C. Bressan, R. R. Teixeira, Bioorg. Med. Chem. Lett. 2016, 26, 2810-2816; d) B. Xiao, J. Yin, M. Park, J. Liu, J. L. Li, E. L. Kim, J. Hong, H. Y. Chung, J. H. Jung, Bioorg. Med. Chem. 2012, 20 4954-4961; e) L. M. Bedoya, E. del Olmo, R. Sancho, B. Barboza, M. Beltrán, A. E. García-Cadenas, S. Sánchez-Palomino, J. L. LópezPérez, E Muñoz, A. San Feliciano, J. Alcamí, Bioorg. Med. Chem. Lett. 2006, 16, 4075-4079; f) F. J. Radcliff, J. D. Fraser, Z. E. Wilson, A. M. Heapy, J. E. Robinson, C. J. Bryant, C. L. Flowers, M. A. Brimble,
Bioorg. Med. Chem. 2008, 16, 6179-6185; g) Y. Ogino, N.Ohtake, Y. Nagae, K. Matsuda, M. Ishikawa, M. Moriya, M. Kanesaka, Y. Mitobe, J. Ito, T. Kanno, A. Ishihara, H. Iwaasa, T. Ohe, A. Kanatani, T. Fukami, Bioorg. Med. Chem. Lett. 2008, 18, 4997-5001; h) M. P. Costi, A. Gelain, D. Barlocco, S. Ghelli, F. Soragni, F. Reniero, T. Rossi, A. Ruberto, C. Guillou, A. Cavazzuti, C. Casolari, S. Ferrari, J. Med. Chem. 2006, 49, 5958-5968; i) B. Proksa, S. Uhrínová, J Adamcová, J. Fuska, Monatsh Chem. 1992, 123, 251-256.

[4] a) D. Mal, P. Pahari, Chem. Rev. 2007, 107, 1892-1918; b) H. Rathwell, M. A. Brimble, Synthesis 2007, 643-662; c) A. S. Mitchell, R. A. Russell Tetrahedron 1995, 51, 5207-5236; d) D. Mal, K. Ghosh, S. Jana, Org. Lett. 2015, 17, 5800-5803; e) Z. Fei, F. E. McDonald, Org. Lett. 2007, 9, 3547-3550; f) M. L. Patil, H. B.Borate, D. E. Ponde, V. H. Deshpande, Tetrahedron 2002, 58, 6615-6620; g) C. Cox, S. J. Danishefsky, Org. Lett. 2000, 2, 3493-3496; h) R. S. Mali, K. N. Babu, J. Org. Chem. 1998, 63, 2488-2492; i) J. N. N. Eildal, J. Andersen, A. S. Kristensen, A. M. Jørgensen, B. Bang-Andersen, M. Jørgensen, K. Strømgaard, J. Med. Chem. 2008, 51, 3045-3048; j) E. Hernández, J. M. Vélez, C. P. Vlaar, Tetrahedron Lett. 2007, 48, 8972-8975.

[5] For some reviews see: a) M. C. Willis, Angew. Chem. Int. Ed. 2010, 49, 6026-6027; b) A. Di Mola, L. Palombi, A. Massa, Curr. Org. Chem. 2012, 16, 2302-2320; c) M. J. Xiong, Z. H. Li, Curr. Org. Chem. 2007, 11, 833-844.

[6] For selected examples see: a) J. M. Cabrera, J. Tauber, M. J. Krische, Angew. Chem. 2018, 130, 1404-1407; Angew. Chem. Int. Ed. 2018, 57, 1390-1393; b) B. Lu, M. Zhao, G. Ding, X. Xie, L Jiang, V. Ratovelomanana-Vidal, Z. Zhang, ChemCatChem 2017, 9, 3989-3996; c) B. Parhi, S. Maity, P. Ghorai, Org. Lett. 2016, 18, 5220-5223; d) Yohda, M.; Yamamoto, Y., Org. Biomol. Chem. 2015, 13, 10874-10880; e) X. Song, Y.-Z. Hua, J.-G. Shi, P.-P. Sun, M.-C. Wang, J. Chang, J. Org. Chem. 2014, 79, 6087-6093; f) R. S. Reddy, I. N. C. Kiran, A Sudalai, Org. Biomol. Chem. 2012, 10, 3655-3661; g) H. Zhang, S. Zhang, L. Liu, G. Luo, W. Duan, W. Wang, J. Org. Chem. 2010, 75, 368-374; h) J. Yang, N. Yoshikai, J. Am. Chem. Soc. 2014, 136, 1674816751; i) D. H. T. Phan, B. Kim, V. M. Dong, J. Am. Chem. Soc. 2009 131, 15608-15609; j) B. Zhang, M.-H. Xu, G.-Q. Lin, Org. Lett. 2009, 11, 4712-4715; k) M. Watanabe, N. Hashimoto, S. Araki, Y. Butsugan, J. Org. Chem. 1992, 57, 742-744; I) B. M. Trost, A. H. Weiss, Angew. Chem. 2007, 119, 7808-7810; Angew. Chem. Int. Ed. 2007, 46, 76647666.

[7] For some reviews see: a) G. Casiraghi, L. Battistini, C. Curti, G. Rassu, F. Zanardi, Chem. Rev. 2011, 111, 3076-3154; b) S. E. Denmark, J. R. Heemstra, Jr., G. L. Beutner, Angew. Chem. 2007, 117, 4760-4777; Angew. Chem. Int. Ed. 2005, 44, 4682-4698; c) Y. Yin, Z. Jiang, ChemCatChem 2017, 9, 4306-4318; d) C. Schneider, F. Abels, Org. Biomol. Chem. 2014, 12, 3531-3543; e) X. Jusseau, L. Chabaud, C. Guillou, Tetrahedron 2014, 70, 2595-2615; f) I. D. Jurberg, I. Chatterjee, R. Tannerta, P. Melchiorre, Chem. Commun. 2013, 49, 4869-4883; g) S. V. Pansare, E. K. Paul, Chem. Eur. J. 2011, 17, 8770-8779; h) C. Curti, A. Sartori, L. Battistini, F. Zanardi, Synlett 2018, 29, 266-281; i) R. Dalpozzo, R. Mancuso, Synthesis 2018, 50, 2463-2472; j) H.-L. Cui, Y.C. Chen, Chem. Commun. 2009, 4479-4486.

[8] a) J. Luo, H. Wang, F. Zhong, J. Kwiatkowski, L.-W. Xu, Y. Lu, Chem Commun. 2013, 49, 5775-5779; b) J. Luo, C. Jiang, H. Wang, L.-W. Xu Y. Lu, Tetrahedron Lett. 2013, 54, 5261-5265; c) J. Luo, H. Wang, F. Zhong, J. Kwiatkowski, L.-W. Xu, Y. Lu, Chem. Commun. 2012, 48, 4707-4709; d) F. Zhong, J. Luo, G.-Y. Chen, X. Dou, Y. Lu, J. Am. Chem. Soc. 2012, 134, 10222-10227; e) Z.-P. Hu, Z. Zhuang, W.-W Liao, J. Org. Chem. 2015, 80, 4627-4637; f) W. Liu, Z.-P. Hu, Y. Yan, W.-W. Liao, Tetrahedron Lett. 2018, 59, 3132-3135.

[9] For examples of AMR of C-3 unfunctionalized phthalides through activation with strong bases see: a) N. J. P. Broom, P. G. Sammes, J. Chem. Soc., Perkin Trans. 1 1981, 465-470; b) W. K. Janowski, R. H. Prager, Aust. J. Chem. 1985, 38, 921-929; for examples of arylogous aldol and Mannich reactions of $\mathrm{C}-3$ unfunctionalized phthalides through 
activation with strong bases see: c) M. A. Ciufolini, M. E. Browne, Tetrahedron Lett. 1987, 28, 171-174; d) J. A. Dibbens, R. H. Prager, C. H. Schiesser, A. J. Wells, Aust. J. Chem. 1985, 38, 913-920.

[10] a) C. M. Starks, C. L. Liotta, M. E. Halpern, Phase-Transfer Catalysis, Fundamentals, Applications, and Industrial Perspectives, Chapman \& Hall, New York, 1994; b) Phase-Transfer Catalysis, Fundamentals, Mechanisms and Syntheses (Ed.: M. E. Halpern), American Chemical Society, Washington, DC, 1997; c) C. M. Starks, C. L. Liotta, PhaseTransfer Catalysis, Principles and Techniques, Academic Press, New York, 1978; d) Handbook of Phase-Transfer Catalysis (Eds.: Y. Sasson, R. Neumann), Chapman \& Hall, London, 1997; e) Albanese, D. Cat Rev. Sci. Eng. 2003, 45, 369-395.

[11] a) R. Schettini, F. De Riccardis, G. Della Sala, I. Izzo, J. Org. Chem. 2016, 81, 2494-2505; b) R. Schettini, B. Nardone, F. De Riccardis, G. Della Sala, I. Izzo, Eur. J. Org. Chem. 2014, 7793-7797; c) R. Schettini, A. D’Amato, F. De Riccardis, G. Della Sala, I. Izzo, Synthesis 2017, 49, 1319-1326; d) G. Della Sala, B. Nardone, F. De Riccardis, I. Izzo, Org Biomol. Chem. 2013, 11, 726-731; f) N. A. De Simone, R. Schettini, C Talotta, C. Gaeta, I. Izzo, G. Della Sala, P. Neri, Eur. J. Org. Chem. 2017, 5649-5659.

[12] G. Della Sala, M. Sicignano, R. Schettini, F. De Riccardis, L. Cavallo, Y. Minenkov, C. Batisse, G. Hanquet, F. Leroux, I. Izzo, J. Org. Chem. 2017, 82, 6629-6637.

[13] M. Sicignano, A. Dentoni Litta, R. Schettini, F. De Riccardis, G. Pierri, C. Tedesco, I. Izzo, G. Della Sala, Org. Lett. 2017, 19, 4383-4386.

[14] D. Aand, S. Karekar, B. Mahajan, A. B. Pawar, A. K. Singh, Green Chem. 2018, 20, 4584-4590.

[15] See Supporting Information for details.

[16] CCDC 1874899 contains the supplementary crystallographic data for 3aa. These data are provided free of charge by The Cambridge Crystallographic Data Centre.

[17] A. Claraz, S. Oudeyer, V. Levacher, Adv. Synth. Catal. 2013, 355, 841 846.

[18] P. E. Stott, J. S. Bradshaw, W. W. Parish, J. Am. Chem. Soc. 1980, 102, 4810-4815

[19] CCDC 1874897 contains the supplementary crystallographic data for 3ad. These data are provided free of charge by The Cambridge Crystallographic Data Centre.

[20] CCDC 1874898 contains the supplementary crystallographic data for 3an. These data are provided free of charge by The Cambridge Crystallographic Data Centre.

[21] G. Haufe, S. Suzuki, H. Yasui, C. Terada, T. Kitayama, M. Shiron, N. Shibata, Angew. Chem. 2012, 124, 12441-12445; Angew. Chem. Int. Ed. 2012, 51, 12275-12279.

[22] After total conversion, $\mathrm{H}_{2} \mathrm{O}(1 \mathrm{~mL})$ was added, and the silylated adduct 6aa was isolated, after extraction and flash-chromatography purification, in high yield ( $88 \%$ yield) along with minor amounts of desilylated product 3 aa (12\% yield). As demonstrated by ${ }^{1} \mathrm{H}$ NMR reaction monitoring in toluene- $d_{6}$, 3aa was formed almost completely within few hours, likely by desilylation with $\mathrm{KOH}$ amount still present in the reaction mixture. At conversion values approximately more than 30 $35 \%$, 6aa was formed exclusively. See Supporting Information for details.

[23] See Supporting Information for experimental details.

[24] In ref. 12 calculations were performed at the M06/TZVP(SMD)//PBE/SVP level of theory.
[25] For discussions on relationships between cation steric accessibility and cation-anion ion separation, with effects on reactivity and selectivity see: a) E. V. Dehmlow in Phase-Transfer Catalysis, Fundamentals, Mechanisms and Syntheses (Ed.: M. E Halpern), American Chemical Society: Washington, DC, 1997, pp. 108-122, and references cited therein; b) E. Weber, F. Vögtle in Host Guest Complex Chemistry Macrocycles - Synthesis, Structures, Applications (Eds.: E. Weber, F. Vögtle), Springer: Berlin, 1985, pp. 1-42; c) E. Reinholz, A. Becker, B. Hagenbruch, S. Schäfer, A. Schmitt, Synthesis 1990, 1069-1071; d) D. Landini, A. Maia in Encyclopedia of Supramolecular Chemistry, Vol. 2 (Eds.: J. L. Atwood, J. W. Steed), Taylor \& Francis, Boca Raton, 2004, pp. 939-949; e) D. Landini, A. Maia, F. Montanari, F. Pirisi, J. Chem. Soc., Perkin Trans. 2 1980, 46-51; f) A. Gobbi, D. Landini, A. Maia, S. Petricci, J. Org. Chem. 1998, 63, 5356-5361; g) A. Maia, D. Landini, S. Petricci, Supramol. Chem. 2000, 12, 203-207.

[26] During this study, DFT analysis has been limited to the exo and endo Diels Alder like transition states, which have been demonstrated to be far more stable than the other possible transition states in the VMMR of butenolides (see ref. 12)

[27] a) L. Falivene, S. M. Kozlov, L. Cavallo, ACS Catal. 2018, 8, 56375656; b) I. Fernández, F. M. Bickelhaupt, Chem. Soc. Rev. 2014, 43, 4953-4967; c) For a detailed energy decomposition analysis see Supporting Information.

[28] A. D. Becke, J. Chem. Phys. 1993, 98, 5648-5652.

[29] a) C. Lee, W. Yang, R. G. Parr, Phys. Rev. B 1988, 37, 785-789; b) B. Miehlich, A. Savin, H. Stoll, H. Preuss, Chem. Phys. Lett. 1989, 157, 200-206.

[30] Gaussian 09, Revision D.01, M. J. Frisch, G. W. Trucks, H. B. Schlegel, G. E. Scuseria, M. A. Robb, J. R. Cheeseman, G. Scalmani, V. Barone B. Mennucci, G. A. Petersson, H. Nakatsuji, M. Caricato, X. Li, H. P. Hratchian, A. F. Izmaylov, J. Bloino, G. Zheng, J. L. Sonnenberg, M Hada, M. Ehara, K. Toyota, R. Fukuda, J. Hasegawa, M. Ishida, T. Nakajima, Y. Honda, O. Kitao, H. Nakai, T. Vreven, J. A. Montgomery, Jr., J. E. Peralta, F. Ogliaro, M. Bearpark, J. J. Heyd, E. Brothers, K. N. Kudin, V. N. Staroverov, T. Keith, R. Kobayashi, J. Normand, K. Raghavachari, A. Rendell, J. C. Burant, S. S. lyengar, J. Tomasi, M. Cossi, N. Rega, J. M. Millam, M. Klene, J. E. Knox, J. B. Cross, V. Bakken, C. Adamo, J. Jaramillo, R. Gomperts, R. E. Stratmann, O. Yazyev, A. J. Austin, R. Cammi, C. Pomelli, J. W. Ochterski, R. L. Martin, K. Morokuma, V. G. Zakrzewski, G. A. Voth, P. Salvador, J. J. Dannenberg, S. Dapprich, A. D. Daniels, O. Farkas, J. B. Foresman, J. V. Ortiz, J. Cioslowski, and D. J. Fox, Gaussian, Inc., Wallingford CT, 2013.

[31] A. Schäfer, H. Horn, R. Ahlrichs, J. Chem. Phys. 1992, 97, 2571-2577.

[32] A. Schaefer, C. Huber, R. Ahlrichs, J. Chem. Phys. 1994, 100, 58295835.

[33] Y. Zhao, D. G. Truhlar, Theor. Chem. Acc. 2008, 120, 215-241.

[34] A. V. Marenich, C. J. Cramer, D. G. Truhlar, J. Phys. Chem. B 2009, 113, 6378-6396 


\section{Entry for the Table of Contents}

\section{FULL PAPER}

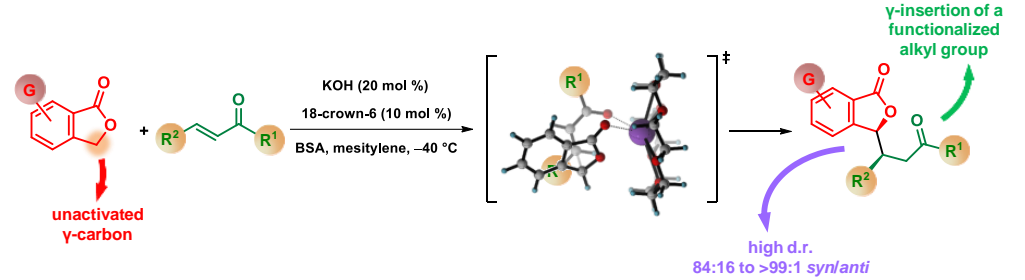

Purely arylogous, mild and diastereoselective: A novel mild, cost-effective and highly diastereoselective methodology, exploiting the arylogous concept, has been developed for introducing an electrophilic group at the unactivated $y$-position of phthalides. DFT calculations support a syn-diastereoselective mechanism involving the participation of $\mathrm{K}^{+} \subset$ crown cation.
Marina Sicignano, Rosaria Schettini, Luisa Sica, Giovanni Pierri, Francesco De Riccardis, Irene Izzo, Bholanath Maity, Yury Minenkov, Luigi Cavallo, * Giorgio Della Sala*

Page No. - Page No.

Unprecedented Diastereoselective Arylogous Michael Addition of Unactivated Phthalides 